\title{
Demokrati - bättre än alternativen? En kommentar till Jason Brennans Against Democracy
}

\author{
PER MOLANDER
}

I ett ofta citerat tal till underhuset i november 1947 förklarade Winston Churchill: "Ingen påstår att demokratin är perfekt eller allvetande. Sålunda har det sagts att demokrati är det värsta styresskicket med undantag för alla de alternativ som från tid till annan har prövats.” Det är värt att notera att Churchill inte gör anspråk på upphovsrätten utan hänvisar till en traderad visdom. Egentligen är det remarkabelt att en aristokratisk högerman som gjorde arroganta formuleringar till en egen konstform framförde en sådan trosbekännelse. Men så var det.

Alla skribenter och politiker i den högra delen av det politiska spektret har inte varit lika positiva. "Demokrati innebär att de outbildade regerar”, hävdade G.K. Chesterton, men han tillade som en sorts reservation att "aristokrati innebär att de illa utbildade regerar" (I93I). Ekonomer som James Buchanan (1954) och Friedrich von Hayek (1948; 2015 [1959]) har velat kringskära demokratin genom att i grundlag undanta vissa ekonomiska frågor från majoritetsbeslut. Det är i denna demokratikritiska tradition som Jason Brennans Against Democracy placerar sig. Den svenska översättningen av boken har fått den mindre provokativa titeln Efter demokratin, möjligen av taktiska skäl (Brennan 2017 [20I6]).

I. Sidhänvisningarna i det följande avser den svenska pocketutgåvan.

Parallellt publicerad i Sven Engström \& Sven Hort (red.), Om Bo Rothstein-forskaren, debattören, livsnjutaren (Arkiv förlag 2019). 
Brennans argument är i korthet att demokratin är ett högst ofullgånget styresskick - väljarna är inkompetenta och i många fall ointresserade, besluten blir illa underbyggda, och politik leder allmänt till fördumning och ökad aggressionsnivå i samhället. Demokratin bör därför ersättas med vad han kallar en epistokrati, ett system där personer som uppfyller vissa kunskapskrav får större inflytande över hur landet styrs. Brennan hävdar att hans förslag är nytt och oprövat; det skulle därmed inte träffas av Churchills kommentar ovan.

\section{Existensen av politiska sanningar}

För Brennan är frågan om bästa styresskick instrumentell till sin karaktär. Det är de institutioner som leder till bäst resultat som ska väljas; något egenvärde finns inte hos ett demokratiskt system. Denna tanke är inte ny; ekonomen Joseph Schumpeter såg på samma sätt demokratin som en metod att fatta kollektiva beslut, inte mer (1942, kapitel 20). Åtskilliga demokratiteoretiker säger emot på den punkten och tilldelar demokratin ett egenvärde. Men detta är en tämligen ren värderingsfråga, där Brennan naturligtvis kan välja ståndpunkt fritt.

Mer problematiskt blir det när han ska omsätta denna instrumentella demokratisyn i praktiken. Om demokratin är en metod bland andra för att uppnå ett bättre samhälle, då måste man också precisera vad som menas med ett bättre samhälle och en bättre politik för att nå dit. Brennan menar att detta är en fråga om sanning och använder sig ymnigt av referenser till den "bästa" politiken, ibland till och med i kombinationen "bättre, väsentligt rättvisare":

[...] det [finns] inget sätt att fördela den politiska makten som i sig självt är rättvist eller orättvist. I stället finns det en förfarandeoberoende sanning om vilka en regerings rätta mål är, om vilka politiska åtgärder regeringar bör genomföra eller vilka resultat regeringar bör sträva efter. Vi bör använda det styrelsesätt, oberoende av hur det ser ut - eller inget styrelsesätt alls - som på bästa sätt kommer fram till denna oberoende sanning (s. 32).

Detta är ett uppseendeväckande påstående. För snart trehundra år sedan påpekade David Hume att steget från fakta till rekommendationer, från 
$\ddot{a} r$ till bör, inte är så enkelt som en del av hans samtida filosofkollegor föreföll tro (I739-40, bok III, del I, avsnitt I). Man kan inte härleda en norm eller en rekommendation direkt ur fakta. Modern logik har givit honom rätt på den punkten; det krävs en överbryggningsprincip för att ta det steget (Schurz 1997).

När Brennan ska konkretisera vad politiska sanningar innebär, handlar det exempelvis om frihandel, abortbegränsningar, statsskuldspolitik och marknadslösningar inom hälso- och sjukvård (s. 239). I klartext menar alltså Brennan utan närmare motivering att det är sant att frihandel är bättre än alternativen, att abort ska vara fri (oklart hur fri), att underskott i statsbudgeten är skadliga och att marknadsalternativ inom hälso- och sjukvård är överlägsna. Låt oss granska dessa påståenden i tur och ordning.

Påståendet om frihandelns överlägsenhet är förvisso en hörnsten i den marknadsliberala opinionsbildningen. På kort sikt finns det också visst stöd för att vinsterna på aggregerad nivå i ett land vid en liberalisering överstiger förlusterna, så att de som förlorar på en förändrad politik kan kompenseras och att befolkningen i stort delar på nettot. Problemet med det argumentet är att denna kompensation erfarenhetsmässigt sällan kommer till stånd. Värre är emellertid att påståendet om frihandelns överlägsenhet inte gäller i ett längre tidsperspektiv, något som den empiriska forskningen har visat (Williamson 20II). Vid I700-talets mitt, när den internationella handeln började ta fart, hade både Indien och Kina var för sig en större industripotential än Europa. Den arbetsfördelning som blev resultatet av den europeiska ekonomiska och militära expansionen ledde till avindustrialisering av de asiatiska länderna som hämmade deras ekonomiska utveckling. Specialiseringen till plantagebaserat jordbruk och extraktiv industri skapade en ojämlikhet i löner och förmögenhet i dessa länder som verkade i samma riktning. Råvarupriser uppvisar också en högre volatilitet än industrivaror, något som även det påverkar tillväxttakten negativt. Här ligger en stor del av förklaringen till det tillväxtgap mellan väst och den övriga världen som vidgades under I8oo-talet och en stor del av 1900-talet. Värt att notera är att de asiatiska länder som först lyckades ta steget in i den industrialiserade världens övre skikt Japan, Sydkorea, Taiwan - inte alls tillämpade en frihandelsstrategi utan 
litade till en aktiv statlig intervention i både hemmamarknad och exportindustri (Wade 2003).

Att abortfrågan är moraliskt komplicerad framgår av det politiska engagemanget för och emot fri abort över stora delar av världen. Långsiktigt finns en tendens mot ökad frihet i detta avseende, men det är naturligtvis nonsens att påstå att det är sant att det är rätt med fri abort. Lagstiftningen måste dessutom precisera under vilka förutsättningar aborträtten gäller.

Statsskuldspolitiken måste på samma sätt baseras på en kombination av fakta, bedömda samband och moralisk hänsyn till kommande generationer. Det finns ingen oomstridd bästa statsskuldspolitik.

En illustration till Brennans sista exempel, marknadslösningar inom hälso- och sjukvårdssektorn, är att det marknadsdominerade amerikanska sjukvårdssystemet har de högsta kostnaderna i världen i relation till BNP per capita och kostar omkring 90 procent mer än i det genomsnittliga OECD-landet. Trots detta imponerar inte den amerikanska sjukvårdens resultat (OECD 20II, 20I7).

Brennans försök att reducera politikens problem till en fråga om sant eller falskt är patetiskt. Praktiskt taget alla politiska problem av någon betydelse förutsätter avvägningar mellan olika gruppers intressen, mellan lång och kort sikt och mellan delvis motstridiga moraliska värden. De förändringar som otvetydigt förbättrar situationen för alla medborgare - vad som med ekonomiskt språkbruk kallas de paretosanktionerade - är få.

Brennans elementära misstag när det gäller sanningsbegreppet och relationen mellan fakta och rekommendationer är tillräckligt för att punktera hela boken, eftersom argumentationen för en epistokrati förutsätter att det finns en politisk sanning som de kunniga medborgarna är särskilt väl skickade att hitta fram till. Här skulle alltså denna text kunna sluta, men låt oss ändå, för samtalets skull, fortsätta analysen. ${ }^{2}$

2. En pikant historisk observation är att idén att det finns en politisk sanning odlades på vänsterkanten under 1960-talet. Herbert Marcuse skrev i essän ”Repressiv tolerans" (1965): "[...] det finns en objektiv sanning som kan upptäckas och formuleras bara genom att man lär och förstår det som existerar och vad som är möjligt och vad som bör göras för att förbättra människans villkor.” 


\section{Andra grundvärderingar}

Det finns en upplysningsfientlig underton i Brennans argumentation som är vanligare hos uttryckligt konservativa skribenter än i den liberala fålla där Brennan placerar sig själv. ${ }^{3}$ Det som är utgångspunkten för hans argument - att väljare i gemen är okunniga - kan ju mötas på två olika sätt. Antingen kan man ta detta för givet och anpassa samhällets institutioner därefter, eller också kan man försöka råda bot på okunnigheten genom utbildning. Brennan väljer det första alternativet och argumenterar samtidigt emot politiskt engagemang och den kunskap som kan följa med ett sådant:

Ibland är det bättre för en persons epistemiska karaktär att hon förblir okunnig och apatisk. Ibland när människor tar in information gör de det på ett biaspräglat och förvrängt sätt. Benägenheten att vara en dålig människa finns där hela tiden, men det är bättre att den förblir latent (s. IIO).

Under kapitelrubriken "Okunniga, irrationella och felinformerade nationalister", plockar Brennan ur litteraturen om kognitiva slagsidor, kunskapsresistens, grupptänkande och andra ofullkomligheter i människans varseblivning. Men dessa ofullkomligheter gäller ju inte bara på det politiska området utan i samhällslivet i stort. Den logiska slutsatsen, om man underkänner medborgaren som väljare, vore att underkänna henne också i rollen som konsument, aktör i det civila samhället och andra situationer i vardagslivet, med vittgående konsekvenser för samhällets organisation.

En annan värdering som återkommer ofta i boken är, föga oväntat, att staten är för stor; den ägnar sig åt fler verksamheter än den borde. Ekonomisk teori har en standardansats för att identifiera situationer där decentraliserat beslutsfattande på individuell basis leder till ineffektiva eller direkt skadliga utfall, samlade under rubriken marknadsmisslyckanden. ${ }^{4}$ I sådana situationer kan man överväga offentliga ingrepp för att realisera utfall som ökar välfärden i samhället. Det kräver en konkret analys av varje situation, i vilken kostnaden för det offentliga ingreppet

3. För några ingångar till denna tradition, se Compagnon 2005, McMahon 200I och Sternhell 2006.

4. Se Molander 1999 och i kondenserad form Molander 20I7, kapitel 9. 
vägs mot vinsten. Brennan betraktar detta som överflödigt och nöjer sig i stället med en rundfrågning i bekantskapskretsen:

Det kanske finns en liten uppsättning problem för vilka människor måste fatta kollektiva beslut. [...] jag [svarar] helt enkelt att den här uppsättningen med all säkerhet är mindre än de problem vi faktiskt underkastar kollektiv styrning. Både mina vänsterinriktade och högerinriktade vänner håller med, för jag hör dem ofta beklaga sig över att människor som tillhör motståndarsidan behandlar sådant som inte borde tillhöra den politiska sfären som politiska frågor. Vi tycks alla hålla med om att politikens område ofta är större än det nödvändigtvis borde vara (s. 322).

Som metod för att besvara en av den politiska ekonomins grundfrågor - gränsdragningen mellan offentligt och privat - imponerar inte detta.

\section{Beteendeantaganden}

Det som karaktäriserar medborgaren i det samhälle som Brennan tecknar är framför allt okunnighet om elementära fakta. Det gäller både fakta om samhällsförhållanden och om vilka alternativ de politiska partierna och kandidaterna faktiskt företräder. Det är inte nog med att kunskaperna är otillräckliga; medborgarna hävdas dessutom vara ointresserade av att inhämta ny kunskap och delta i deliberativa samtal (s. IOO). Sådana samtal hävdas av Brennan till och med kunna leda till moralisk eller politisk skepticism eller nihilism (s. 99). En del av hans påståenden är oomstridda, medan andra bygger på en vinklad återgivning av litteraturen. ${ }^{5}$

I frågan om vad som styr människors agerande på den sociala arenan vacklar Brennan. På ett ställe skriver han: "Individer fattar sina egna beslut med hänsyn till sina individuella motiv", vilket låter snarlikt den ekonomiska teorins karaktärisering av homo oeconomicus. På andra ställen hävdar han tvärtom att altruistiska motiv är viktiga för människors beslut i sociala sammanhang. Han säger sig till och med ha presenterat "överväldigande evidens" för detta. Evidensen består av två (2) referenser, en bok av Bryan Caplan (2007) och en uppsats av Feddersen med flera

5. För en mer positiv läsning av litteraturen om deliberativa samtal, se t.ex. Curato m.fl. 2017. 
(2009). Uppsatsen är en matematisk modell som har testats i ett laboratorieexperiment. Caplans bok handlar huvudsakligen om okunniga väljare, det vill säga det som är huvudtemat i Brennans egen bok. Många väljare uppger att de röstar för att gynna vad de uppfattar som samhällsintressen och anger enligt Caplan och Brennan felaktiga motiv för det, vilket då sägs bekräfta deras okunnighet. Men en annan, högst plausibel förklaring är att de röstar i eget intresse, samtidigt som de klär detta egenintresse i altruistisk dräkt. Producenter som önskar gränsskydd mot utländsk konkurrens brukar sällan anföra den egna vinsten som huvudargument utan hänvisar i stället till beredskapsskäl eller regionalpolitik. Någon överväldigande evidens för att altruistiska motiv skulle dominera när medborgarna lägger sina röster presenterar inte Brennan. Det vore också märkligt, givet den omfångsrika statsvetenskapliga och ekonomiska litteratur som indikerar att gruppintressena dominerar.

\section{Vilken kunskap?}

Brennan hävdar som sagt att väljarnas inkompetens gör åtskilliga av dem mindre väl skickade att fatta politiska beslut, och att rätten att vara med och påverka politikens utformning bör inskränkas till den mer kompetenta delen av dagens valmanskår. Han jämför med rörmokare, frisörer och läkare och ställer den retoriska frågan om vi som bara har genomsnittlig kunskap på dessa områden skulle ifrågasätta sådana yrkesutövares professionella beslut. Frågan är då vad som motsvarar dessa gruppers yrkeskunnande på politikens område. Enligt Brennan är det samhällsvetenskaperna och, förefaller det, i synnerhet nationalekonomi som bör vara obligatoriska ämnen för att väljaren ska kunna bli kompetensförklarad. En naturlig motfråga är varför bara samhällsvetenskaperna nämns. En välgrundad position i sakfrågan om kärnkraftens framtid kräver ingående kunskaper i kärnteknik, energiförsörjningsalternativ, riskbedömningar med mera. En av vår tids stora frågor, klimatpolitiken, förutsätter kunskaper om atmosfärfysik, biosfärens svar på temperaturhöjningar, styrmedel inom energipolitiken och mycket annat för att man ska kunna ta ställning. En konsekvent tillämpning av Brennans kunskapskrav skulle lämna kvar en mycket liten minoritet av befolkningen som kvalificerade väljare. 
Brennans krav är emellertid inte bara för snävt definierat utan också inadekvat. De flesta val i demokratier handlar nämligen inte om enskilda sakfrågor. Undantagen är folkomröstningar om enskildheter, som omröstningen om kärnkraften i Sverige 1980, om medlemskap i EU I994 eller den irländska omröstningen i abortfrågan 20I8. I alla dessa fall föregicks omröstningarna av intensiv och bred kunskapsspridning och debatt. Men redan i dessa undantagsfall kan man konstatera vad som påpekades i inledningen ovan, nämligen att det inte handlar bara om kunskap utan i hög grad också om moraliska eller genuint politiska ställningstaganden.

I normalfallet handlar det inte om enskildheter. Medborgarna väljer partier och i varierande utsträckning personer. Valen bygger på allmänna föreställningar om vad partierna står för, ibland på bedömningar av personer. Väljarna kan förvisso ha fel beträffande var partierna står i enskilda frågor, men den allmänna bilden av var partierna ligger på skalan mellan höger och vänster, hur seriöst de tar på miljöfrågorna och så vidare torde merparten av väljarna ha en tämligen god uppfattning om.

Det är de valda ombuden som sedan har att ta ställning i sakfrågor. Politikerna är märkvärdigt frånvarande i Brennans diskussion. Även bland dem finns naturligtvis kunskapsbrister, men normalpolitikern löser detta genom att specialisera sig på vissa sakområden och skaffa sig en djupare kunskap på dem. Både i utarbetandet och i implementeringen av politiken tar beslutsfattarna vidare hjälp av experter från förvaltningen, mer eller mindre politiskt sorterade, beroende på vilket politikområde det gäller. Myndigheterna engagerar i sin tur ofta externa experter från den akademiska sfären eller andra områden. Denna kunskapskedja från väljare till experter gör Brennans kritik irrelevant.

\section{Alternativen}

Brennan hävdar sig vilja jämföra dagens demokratiska system med epistokratin på lika villkor, det vill säga att han vill undvika att jämföra en verklighet med ett idealt alternativ. Den ambitionen lever han knappast upp till, givet att han ägnar åtta kapitel åt en tämligen aggressiv opinionsbildning mot demokratin och ett skissartat kapitel åt alternativet. 
Alternativet har dessutom suddiga konturer. I förordet säger han sig vilja ge kompetenta samhällsmedborgare "en smula" mer politisk makt än mindre kompetenta och kunniga medborgare (s. iv). Men om det bara handlar om en smula, lär skillnaden inte bli så stor. Han öppnar också i huvudtexten för betydligt större förändringar.

Inte ens i det kapitel där alternativen presenteras är Brennan särskilt precis. Han har två huvudalternativ, ett epistokratiskt veto och en graderad rösträtt. Vetomodellen innebär att man skapar ett epistokratiskt råd med höga kvalifikationskrav. Rådet har ingen makt att lagstifta utan kan bara lägga in veto mot lagstiftning som den underkänner på basis av sin egen kompetens. Han refererar till USA:s högsta domstol som en förebild, med den skillnaden att domstolen har att uttolka konstitutionen, medan det epistokratiska rådet skulle ha det bredare mandatet att förkasta förslag som det på en eller annan grund finner dåliga.

Erfarenheterna från Högsta domstolen illustrerar problemen med konstruktionen. Även om ledamöterna rekryteras på någon form av expertbasis, är det oundvikligt att bedömningar av författningsenlighet får politisk karaktär. Utnämningarna av ledamöter blir då också politiserade, och domstolen förlorar sin tilltänkta roll av balanserande makt. I fallet Roe vs. Wade beslutade den amerikanska Högsta domstolen 1973 att en gravid kvinna under vissa villkor har frihet att bestämma om barnet ska födas. De utnämningar som den republikanska majoriteten godkänt respektive (i skrivande stund) avser att godkänna innebär att domstolen kan komma att domineras av jurister som är motståndare till den fria aborten. Det har inte framkommit någon ny empiri som skulle motivera en sådan förändring; det skulle i så fall handla om ett rent politiskt ställningstagande.

I svagare form har vi sett samma problem i den svenska riksbanksledningen, dit statssekreterare gått och varifrån statssekreterare också har rekryterats. Politiseringsproblemet skulle självfallet bli än mer uttalat med det betydligt bredare och otydligare mandat som ett epistokratiskt råd skulle få.

Huvudmodellen för Brennan är dock den graderade rösträtten (s. 282f). Om en medborgare ska anses kvalificerad att rösta eller inte hänger på ett kunskapstest. Den som klarar provet får behålla sin röst. 
Alternativt kan man tänka sig att man kvalificerar sig för fler röster genom utbildning - fem extra röster för den som går ut high school, femton för den som har genomgått en forskarutbildning.

Som komplement kan Brennan tänka sig ekonomiska incitament. Den som klarar testet får en skattereduktion på I ooo dollar. En annan möjlighet är att den som inte klarar testet ändå får rösta mot erläggande av en avgift på 2 ooo dollar.

En vidareutveckling, som Brennan inte nämner men som ligger i förlängningen, skulle kunna vara att man kombinerar ett system med flera röster och avgifter, så att den som erlägger en multipel av grundavgiften också skulle få ett motsvarande antal röster. Gränsen på sexton röster förefaller också godtycklig - varför inte sätta den vid exempelvis fyrtio röster i stället? Då skulle vi få ett system som vi känner från vår egen historia: den fyrtiogradiga skalan, som rådde före den allmänna rösträttens införande för hundra år sedan. Skillnaden är den att den fyrtiogradiga skalan baserades på taxeringen, medan det här systemet skulle kräva att den som vill utnyttja hela skalan också skulle få betala ett motsvarande belopp - dock inget hinder för förmögnare skikt. En mer adekvat titel på den svenska översättningen av Brennans bok hade kanske varit "Före demokratin”.

En avgörande fråga för bedömningen av Brennans epistokratiska alternativ är hur den framröstade församlingen kan förväntas fatta beslut. För Brennan är detta inget problem; självklart skulle den fatta beslut med samhällets bästa för ögonen. Han hänvisar ännu en gång till publikationerna om altruistiskt röstande (s. 302), som vi dock har sett utgöra ett tämligen skakigt underlag. Hur människor röstar i ett demokratiskt system där det finns en generell jämlikhetsnorm säger dessutom föga om hur de skulle rösta i ett system med en institutionaliserad rangordning mellan medborgarna. Om man vill föreställa sig utfallet, bör man i stället gå till historien. Präglades adelns och prästerskapets beslut i ståndsriksdagen av hänsyn till hela folkets intressen? Präglades den politiska elitens beslut under den fyrtiogradiga skalans epok av hänsyn till de mindre bemedlade samhällsskiktens intressen? Knappast.

Det finns i själva verket aktuella erfarenheter som visar vilken riktning utvecklingen skulle ta. Statsvetaren Martin Gilens har i boken Affluence 
and Influence (2012) visat att förmögna personer under senare decennier fått en allt starkare representation i den amerikanska kongressen. Brennan kommenterar Gilens arbete (s. 264f) och ser det som "ett skäl att glädjas”. De förmögnare personerna är ju i genomsnitt mer informerade än genomsnittsmedborgaren, och Gilens resultat är därför i viss mening en indikation på att Brennans epistokratiska system de facto är under införande, och då som ett direkt resultat av samhällets politisk-ekonomiska dynamik utan några författningsändringar. Besvärande för hans argumentation är dock att Gilens samtidigt visar att den förda politiken i växande utsträckning har anpassats till de förmögnare skiktens intressen, alltså ett vederläggande av tesen att altruism skulle råda i den politiska sfären. En bekräftelse ligger i den reala utvecklingen för olika inkomstskikt i USA under perioden 1970-20I5 - en tredubbling för den översta percentilen, en fördubbling för den översta decilen och ingen ökning alls för de 90 procenten därunder (Hassler 20I8, figur 2).

\section{Inkonsistens i argumentationen}

Till ovannämnda brister i Brennans argumentation kommer en besvärande brist på konsistens i antaganden och argument. Han utgår som konstaterats på ett ställe från individuella motiv som styrande, medan han på andra hävdar att altruism dominerar. Sanningen i detta fall är att människor uppvisar både snävt egoistiska och altruistiska drag, att befolkningen är heterogen i det här avseendet, att beteendet är situationsberoende och att det också kan förändras över tid för en och samma individ.

Ett annat exempel gäller demokrati och makt. Brennan spenderar åtskilliga sidor på att slå fast att den enskilde medborgaren inte har någon makt i en demokrati, att en sådan föreställning är illusorisk och att medborgarnas benägenhet att gå och rösta alltså grundas på en lögn (passim, framför allt kapitel 4). På andra ställen argumenterar han upprört över att demokratin ger människor makt över andra, vilket leder till mer eller mindre långtgående övergrepp mot den enskildas integritet (s. I75, I89). Vad som gäller i detta fall är att en enskild individs makt bara i sällsynta undantagsfall blir direkt utslagsgivande i ett val men att 
grupper av väljare naturligtvis har större möjligheter till påverkan. Kollektivt handlande är överhuvudtaget ett fenomen som Brennan har problem att hantera med sitt individualiserade sätt att argumentera.

Den gemensamma nämnaren för tvetydigheter av det här slaget är att Brennan i texten väljer det perspektiv som för tillfället passar hans argumentation bäst.

\section{Sammanfattning}

Brennans huvudargument bygger på ett elementärt misstag - att utformning av institutioner och politik går att reducera till frågor om sant och falskt. Med detta misstag faller hela konstruktionen. Det alternativ han förordar är vidare inte nytt. Vad det handlar om är en form av meritokrati, som i realiteten får starkt plutokratisk karaktär, i synnerhet om man öppnar för de ekonomiska inslag i kvalificeringsproceduren som han vill införa. Till detta ska läggas inkonsistensproblem i själva argumentationen. Det är tveksamt om Brennan själv skulle bli godkänd i det kompetenstest som är kärnan i det system han förordar.

Institutionerna i de existerande demokratierna kan förvisso förbättras. Men uppslag till förbättringar måste sökas i andra riktningar. Som inte minst utvecklingen i USA visar är det förändringar utanför de offentliga institutionerna som ligger bakom de allvarligaste hoten mot demokratin och som demokratin måste skydda sig mot, inte några inneboende defekter i demokratin som sådan.

\section{Referenser}

Brennan, Jason (2017 [2016]). Efter demokratin. Stockholm: Timbro. Originaltitel: Against Democracy.

Buchanan, James (1954). "Economic Policy, Free Institutions, and Democratic Process", Io, box 8, folder 9, Mont Pèlerin Society Records.

Caplan, Bryan (2007). The Myth of the Rational Voter. Princeton: Princeton University Press.

Chesterton, G.K. (1931). New York Times I februari i931, del 5, s. I.

Compagnon, Antoine (2005). Les antimodernes de Joseph de Maistre à Roland Barthes. Paris: Gallimard. 
Curato, Nicole m.fl. (2017). "Twelve Key Findings in Delberative Democracy Research", Daedalus $\mathrm{I} 46,3$, s. $28-38$. DoI: https://doi.org/Io.II62/DAED_a_00444

Feddersen, Timothy m.fl. (2009). "Moral Bias in Large Elections: Theory and Experimental Evidence", American Political Science Review 103, 2, s. 175-192. DOI: https://doi.org/IO.IOI7/Soo03055409090224

Gilens, Martin (2012). Affluence and Influence. Economic Inequality and Political Power in America. Princeton: Princeton University Press.

Hassler, John (2018). "Comment on J.K. Pareliussen, M. Hermansen, C. André and O. Causa: Income Inequality in the Nordic Countries from an OECD Perspective", Nordic Economic Policy Review 2018, s. 62-65.

von Hayek, Friedrich (1948). "Individualism: True and False", föreläsning vid University College i Dublin 17 december 1945, i Individualism and Economic Order. Chicago: University of Chicago Press.

von Hayek, Friedrich (2015 [1959]). Frihetens grundvalar. Stockholm: Timbro. Originaltitel: The Constitution of Liberty.

Hume, David (1739-40). A Treatise of Human Nature. Flera senare utgåvor.

Marcuse, Herbert (I965). "Repressive tolerance", i Wolff, Robert Paul, Moore, Barrington \& Marcuse, Herbert, Kritik der reinen Toleranz. Frankfurt am Main: Suhrkamp.

McMahon, Darrin M. (200I). Enemies of the Enlightenment. The French Counter-Enlightenment and the Making of Modernity. Oxford: Oxford University Press.

Molander, Per (1999). Den ättafaldiga vägen. Motiv för offentliga åtaganden. Stockholm: SNS Förlag.

Molander, Per (2017). Condorcets misstag. Hoten mot staten och demokratin. Stockholm: Weyler.

OECD (20II). Health at a Glance 20II: OECD Indicators. Paris: OECD Publishing.

OECD (2017). OECD Health-Statistics 20I7, från http://www.oecd.org/.

Schumpeter, Joseph A. (1942). Capitalism, Socialism and Democracy. New York: Harper $\&$ brothers.

Schurz, Gerhard (1997). The Is-Ought Problem. An Investigation in Philosophical Logic. Dordrecht: Kluwer.

Sternhell, Zeev (2006). Les anti-Lumières. Du XVIII siècle à la guerre froide. Paris: Fayard. Wade, Robert (2003). Governing the Market. Economic Theory and the Role of Government in East Asian Industrialization. Princeton: Princeton University Press.

Williamson, Jeffrey G. (20II). Trade and Poverty. When the Third World Fell Behind. Cambridge: MIT Press. 
I väntan på den engelska Festschriften, den definitiva biografin eller de självförhärligande memoarerna kommer här för första gången en samling porträtt av ett tjugotal svenska forskare, författare och vänner till den internationellt mest uppmärksammade svenska statsvetaren, den kontroversielle samhällsdebattören Bo Rothstein.

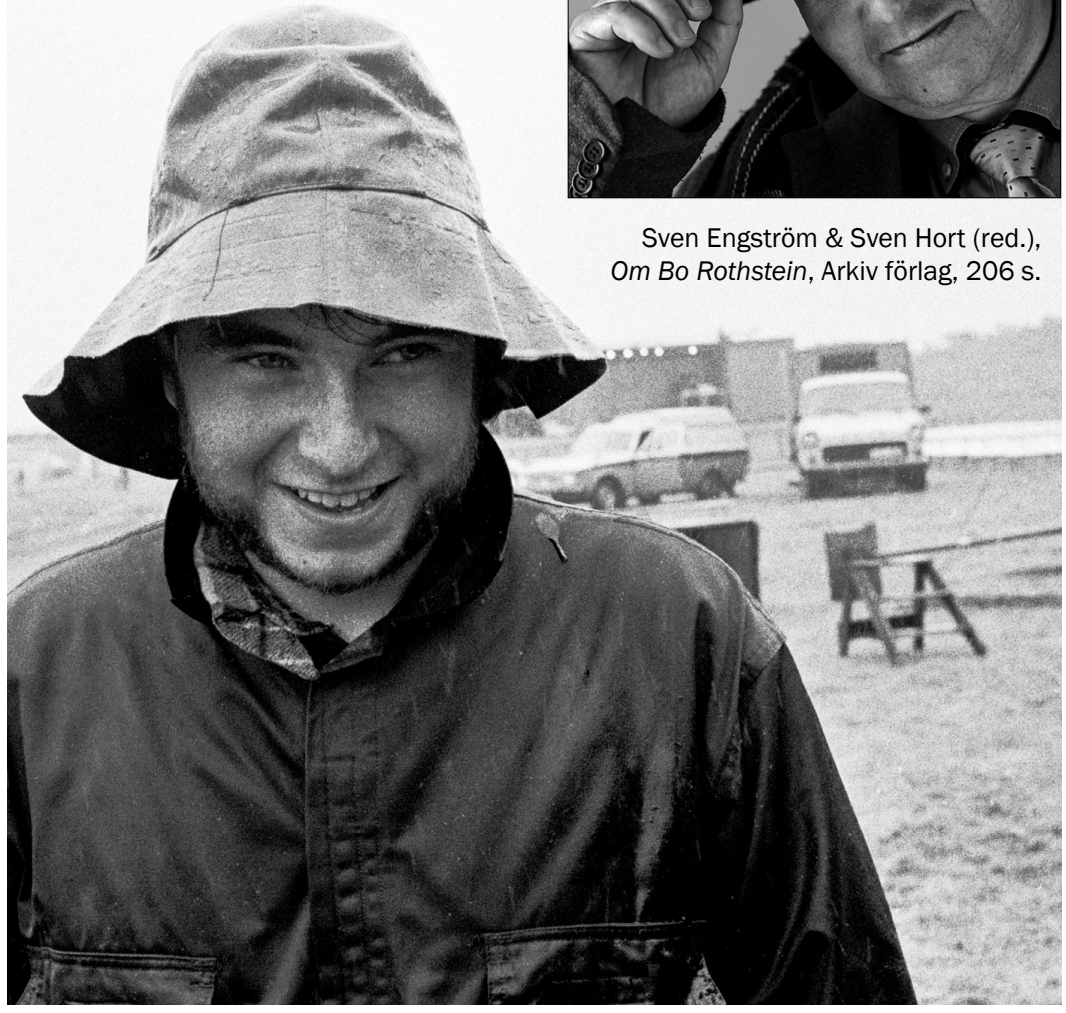

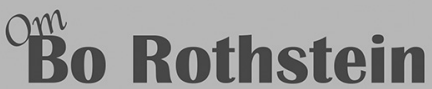

forskaren, debattören, livsnjutaren Sven Engström \& Sven Hort (red.)

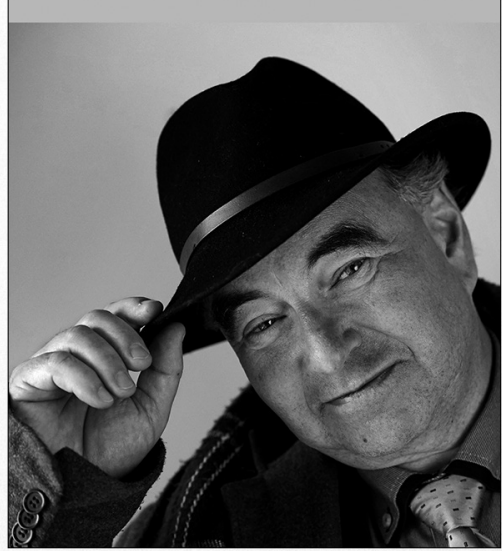

Sven Engström \& Sven Hort (red.), Om Bo Rothstein, Arkiv förlag, 206 s.

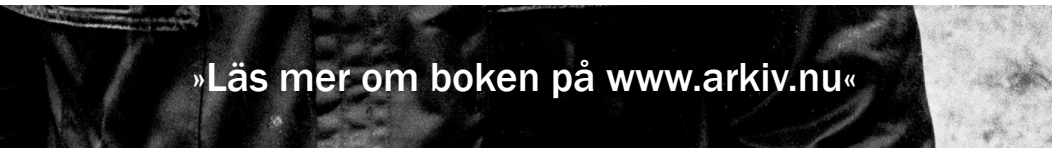

